\title{
Effect of the chemical composition at the memory behavior of $\mathrm{Al} / \mathrm{BST} / \mathrm{SiO}_{2} / \mathrm{Si}$-gate-FET structure
}

\author{
Ala'eddin A. Saif $\cdot$ Z. A. Z. Jamal • \\ P. Poopalan
}

Received: 19 July 2011/Accepted: 17 August 2011/Published online: 2 September 2011

(c) The Author(s) 2011. This article is published with open access at Springerlink.com

\begin{abstract}
The effect of the chemical composition of the ferroelectric barium strontium titanate (BST) on the memory window behavior of $\mathrm{Al} / \mathrm{BST} / \mathrm{SiO}_{2} / \mathrm{Si}$-gate-field effect transistor structure has been investigated. Nanocrystalline $\mathrm{Ba}_{x} \mathrm{Sr}_{1-x} \mathrm{TiO}_{3}$ thin films with different $x$ values have been fabricated as metal-ferroelectric-insulator-semiconductor (MFIS) and metal-ferroelectric-metal (MFM) configurations using a sol-gel technique. The variation of the dielectric constant $(\varepsilon)$ and $\tan \delta$ with frequency for MFM samples have been studied to ensure the dielectric quality of the material. At low frequencies, $\varepsilon$ increases as the strontium content decreases, whereas at high frequencies, it shows the opposite variation, which is attributed to the dipole dynamics. The ferroelectricity of the BST within MFM structure has been investigated using $\mathrm{C}-\mathrm{V}$ characteristics, which show that the ferroelectric hysteresis strength increases as the strontium content decreases. The ferroelectric memory behavior of the MFIS samples has been investigated using $\mathrm{C}-\mathrm{V}$ characteristics. The results show that the memory window width increases as the strontium content decreases; this is attributed to the grain size and dipole dynamics effect.
\end{abstract}

Keywords BST thin films - Dielectric properties . Ferroelectric hysteresis · Memory window · MFIS-FET

\section{Introduction}

In the past few years, ferroelectric random access memories (FRAMs) have been studied extensively due to their

A. A. Saif $(\bowtie) \cdot$ Z. A. Z. Jamal · P. Poopalan

Microfabrication Cleanroom, School of Microelectronic

Engineering, Univerisity Malaysia Perlis, 02000 Kuala Perlis,

Perlis, Malaysia

e-mail: alasaif82@hotmail.com potential advantages, such as non-volatility, unlimited write cycles, and low power consumption. In particular, nondestructive read out (NDRO) FRAM, which has a transistor as a memory cell, has high attention, since the ferroelectric gate offers simpler circuits and excellent performance (Roy et al. 2008; Wang et al. 2003). Among ferroelectric materials, barium strontium titanate (BST) in thin-film form is considered to be one of the most promising candidates for FRAM applications due to its desirable properties such as high permittivity, and relatively high remnant polarization (Ru-Bing et al. 2005).

The barium-to-strontium (Ba:Sr) ratio in BST thin films plays a significant role at the nanostructure and electrical properties. The Curie temperature of BST thin films varies through a long range of values depending on the $\mathrm{Ba}: \mathrm{Sr}$ ratio (Ru-Bing et al. 2005), which in turn controls the phase of the film, i.e., to be in ferroelectric (with a tetragonal lattice) or paraelectric (with a cubic lattice) phase. Furthermore, the size of BST grains is directly related to the Ba:Sr ratio, as $\mathrm{Sr}$ ions increases in the lattice the grain size decreases (Saif and Poopalan 2010); however, the grain size is directly related to the domain wall (Arlt et al. 1985); as a result, the ferroelectric properties of the material change.

Relatively few studies reported the electrical properties for BST as a metal-ferroelectric-semiconductor (MFS) junction (Panda et al. 2002; Jha et al. 2008; Agarwal et al. 2001). This is attributed to the difficulty in the deposition process directly onto silicon, high trap densities, and the diffusion of elements into silicon (Lee et al. 2005; Tang et al. 2007). Hence, to overcome these difficulties, an insulating buffer layer between the ferroelectric layer and the silicon layer has been suggested. In the current work, BST thin films with different Ba:Sr ratios have been fabricated in a Al/BST/ $\mathrm{SiO}_{2} / \mathrm{Si}$ configuration to study the effect of the chemical composition at the memory window behavior. 


\section{Experiment}

Three solutions with different proportions of $\mathrm{Ba}: \mathrm{Sr}$ (50:50, 70:30 and 80:20) were prepared using barium acetate, strontium acetate, and titanium (IV) isopropoxide as the starting materials; the preparation details for the solutions can be found in Saif and Poopalan (2011). Two sets of samples were prepared: (1) a metal-ferroelectric-metal (MFM) configuration where a $\mathrm{Pt} / \mathrm{SiO}_{2} / \mathrm{Si}$ structure was used as the substrate and (2) a metal-ferroelectric-insulatorsemiconductor (MFIS) configuration where a $\mathrm{SiO}_{2} / \mathrm{Si}$ structure was used as the substrate. The film preparation procedure is reported by Saif and Poopalan (2011). The film thickness has been measured using the same procedure mentioned by Saif and Poopalan (2011); the average thickness of both sample sets is $400 \mathrm{~nm}$. For the electrical measurement, in both sets, dots of $\mathrm{Al}$ with an area of $7.85 \times 10^{-3} \mathrm{~cm}^{2}$ were deposited on top of the films as the top electrode using a shadow mask via physical vapor deposition (PVD). For the MFIS samples, the backside of the silicon substrates was etched in hydrofluoric acid and was metallized by depositing a 140-nm-thick Al layer to represent the backside electrode. The crystallization of the material was determined using an X-Ray diffractometer (XRD) with a $\mathrm{CuK} \alpha$ radiation source $(\lambda=1.54 \AA)$, operated at a voltage $40 \mathrm{kV}$ with a current of $40 \mathrm{~mA}$. The dielectric characteristics were performed by an impedance/ gain-phase analyzer (Solartron 1260) in the frequency range of $10 \mathrm{~Hz}-1 \mathrm{MHz}$ at room temperature. $\mathrm{C}-\mathrm{V}$ and $\mathrm{I}-\mathrm{V}$ measurements were performed using a Keithley 4200 semiconductor parameter analyzer.

\section{Results and discussion}

Figure 1 shows XRD patterns of $\mathrm{Ba}_{0.5} \mathrm{Sr}_{0.5} \mathrm{TiO}_{3}, \mathrm{Ba}_{0.7}$ $\mathrm{Sr}_{0.3} \mathrm{TiO}_{3}$, and $\mathrm{Ba}_{0.8} \mathrm{Sr}_{0.2} \mathrm{TiO}_{3}$ films. From Fig. 1 it can be seen that the diffraction peaks are (1 000$),\left(\begin{array}{lll}1 & 1 & 0\end{array}\right),\left(\begin{array}{lll}1 & 1 & 1\end{array}\right)$, (2 000$),\left(\begin{array}{lll}2 & 1 & 0\end{array}\right)$, and $\left(\begin{array}{lll}2 & 1 & 1\end{array}\right)$ within the $2 \theta$ range from $20^{\circ}$ to $60^{\circ}$, which confirms that the films are crystallized with a perovskite structure. The measured lattice parameters of the samples are listed in Table 1. It is observed that the lattice parameters decrease with an increasing strontium content; this is attributed to the fact that the ionic radius of $\mathrm{Sr}$ is smaller than that of $\mathrm{Ba}$. Table 1 shows that the lattice constants for $\mathrm{Ba}_{0.5} \mathrm{Sr}_{0.5} \mathrm{TiO}_{3}$ are equal, which reveals that it has simple cubic structure, whereas, for $\mathrm{Ba}_{0.7} \mathrm{Sr}_{0.3} \mathrm{TiO}_{3}$ and $\mathrm{Ba}_{0.8} \mathrm{Sr}_{0.2} \mathrm{TiO}_{3}$ films, c-axis lattice constant is larger than the a-axis lattice constant. This suggests that the crystal structure for these films is tetragonal at room temperature.

In order to ensure the dielectric quality of the material, the dielectric permittivity $(\varepsilon)$ and loss tangent $\left(\tan \delta=\varepsilon^{\prime \prime} / \varepsilon^{\prime}\right)$

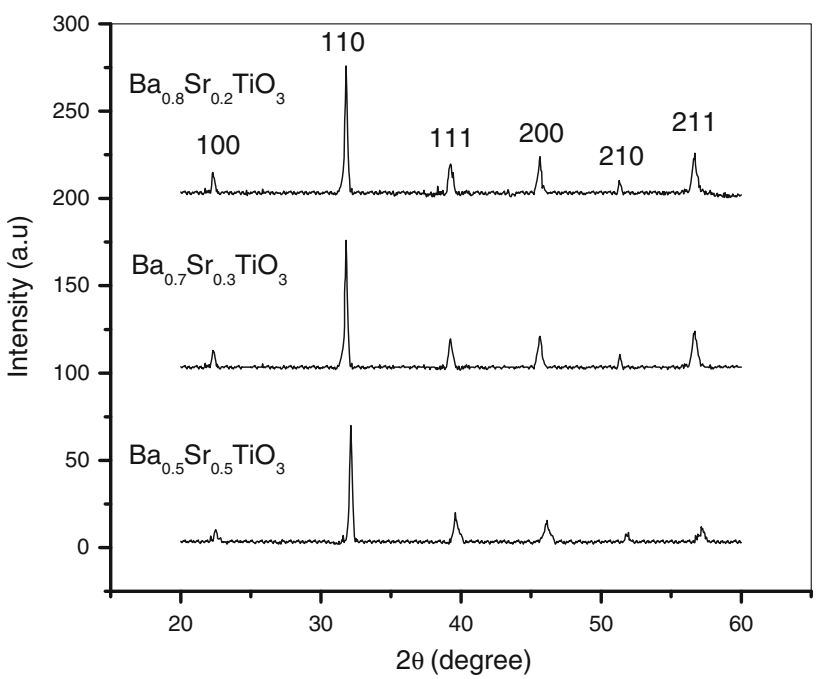

Fig. 1 XRD patterns of $\mathrm{Ba}_{0.5} \mathrm{Sr}_{0.5} \mathrm{TiO}_{3}, \quad \mathrm{Ba}_{0.7} \mathrm{Sr}_{0.3} \mathrm{TiO}_{3}$, and $\mathrm{Ba}_{0.8} \mathrm{Sr}_{0.2} \mathrm{TiO}_{3}$ films

for MFM samples were studied as a function of frequency. Figure 2 shows the variation of $\varepsilon$ with frequency plots for the films used in this work at room temperature. It is observed that the value of $\varepsilon$ for all $\mathrm{Ba}: \mathrm{Sr}$ ratios decreases as the frequency increases and attains a constant limiting value $\varepsilon_{\infty}$ (high-frequency value of $\varepsilon$ ). This can be explained according to the behavior of the dipole movement, the dielectric permittivity related to free dipoles oscillating in the presence of an alternating electric field. At very low frequencies $(f<1 / \tau, \tau$ is the relaxation time), dipoles follow the electric field. As the frequency increases, dipoles begin to lag behind the field and $\varepsilon$ slightly decreases. When the frequency reaches the characteristic frequency $(f=1 / \tau)$, the dielectric constant drops (relaxation process). At very high frequencies $(f>1 / \tau)$, dipoles can no longer follow the field and $\varepsilon \approx \varepsilon_{\infty}$ (Tripathi et al. 2010).

It can be seen in Fig. 2 that at low frequencies the value of $\varepsilon$ increases as the strontium content decreases. This can be explained according to the lattice shape and the presence of the dipoles in the BST lattice. As discussed earlier in this article, the $\mathrm{Ba}_{0.5} \mathrm{Sr}_{0.5} \mathrm{TiO}_{3}$ film is crystallized in a simple cubic structure, while $\mathrm{Ba}_{0.7} \mathrm{Sr}_{0.3} \mathrm{TiO}_{3}$ and $\mathrm{Ba}_{0.8} \mathrm{Sr}_{0.2} \mathrm{TiO}_{3}$ crystallized with a tetragonal perovskite structure. That explains the low dielectric constant value for $\mathrm{Ba}_{0.5} \mathrm{Sr}_{0.5} \mathrm{TiO}_{3}$ at low frequencies compared with the other ratios, whereas the tetragonal phase for $\mathrm{Ba}_{0.7} \mathrm{Sr}_{0.3} \mathrm{TiO}_{3}$ and $\mathrm{Ba}_{0.8} \mathrm{Sr}_{0.2} \mathrm{TiO}_{3}$ films leads to the presence of a valuable number of permanent dipoles within their lattice, which explains the high value of their dielectric constant. Furthermore, the high value of $\varepsilon$ for $\mathrm{Ba}_{0.8} \mathrm{Sr}_{0.2} \mathrm{TiO}_{3}$ compared with $\mathrm{Ba}_{0.7} \mathrm{Sr}_{0.3} \mathrm{TiO}_{3}$ can be attributed to the longer permanent dipoles, since the c/a ratio for $\mathrm{Ba}_{0.8} \mathrm{Sr}_{0.2} \mathrm{TiO}_{3}$ is larger than that for $\mathrm{Ba}_{0.7} \mathrm{Sr}_{0.3} \mathrm{TiO}_{3}$. 
Table 1 Lattice parameters of $\mathrm{Ba}_{0.5} \mathrm{Sr}_{0.5} \mathrm{TiO}_{3}, \mathrm{Ba}_{0.7} \mathrm{Sr}_{0.3} \mathrm{TiO}_{3}$, and $\mathrm{Ba}_{0.8} \mathrm{Sr}_{0.2} \mathrm{TiO}_{3}$ films

\begin{tabular}{lllll}
\hline Sample & $\mathrm{a}(\AA)$ & $\mathrm{c}(\AA)$ & c/a & Structure phase \\
\hline $\mathrm{Ba}_{0.5} \mathrm{Sr}_{0.5} \mathrm{TiO}_{3}$ & 3.9471 & 3.9471 & 1 & Simple cubic \\
$\mathrm{Ba}_{0.7} \mathrm{Sr}_{0.3} \mathrm{TiO}_{3}$ & 3.9771 & 3.9883 & 1.003 & Tetragonal \\
$\mathrm{Ba}_{0.8} \mathrm{Sr}_{0.2} \mathrm{TiO}_{3}$ & 3.9805 & 4.0173 & 1.0092 & Tetragonal \\
\hline
\end{tabular}

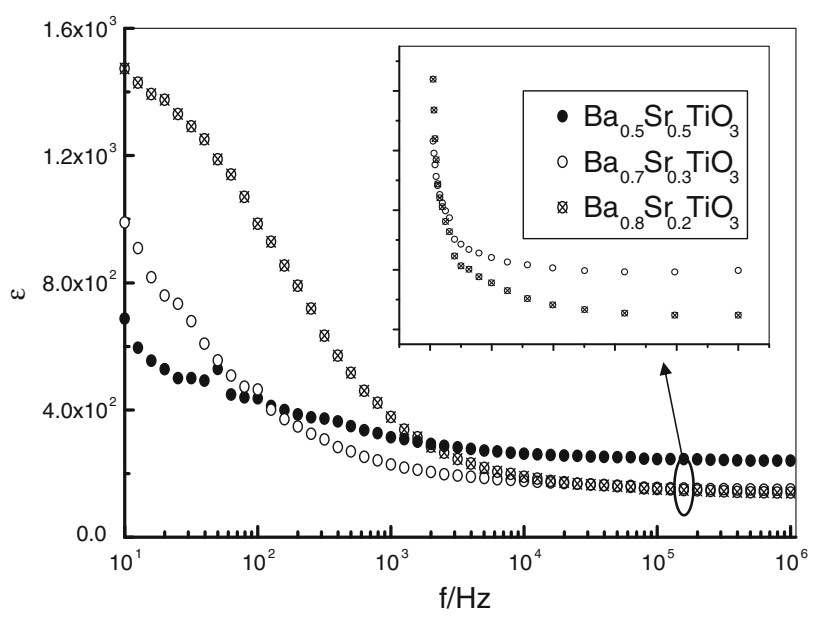

Fig. 2 Variation of $\varepsilon$ with frequency for $\mathrm{Ba}_{0.5} \mathrm{Sr}_{0.5} \mathrm{TiO}_{3}, \mathrm{Ba}_{0.7} \mathrm{Sr}_{0.3} \mathrm{TiO}_{3}$, and $\mathrm{Ba}_{0.8} \mathrm{Sr}_{0.2} \mathrm{TiO}_{3}$ thin films within the MFM structure

On the other hand, at high frequencies, the dielectric constant variation with strontium content becomes the opposite of that observed at low frequencies, i.e. $\varepsilon$ decreases as the strontium content decreases. This may be explained considering the dipole elongation responding to the applied electric field. As an AC electric field is applied at BST lattice, it creates a new dipoles, reorients the permanent dipoles to the direction of the applied filed, and causes an induced shift to the $\mathrm{Ti}$ ions for the dipoles that already have the same orientation of the applied field in case of $\mathrm{Ba}_{0.7} \mathrm{Sr}_{0.3} \mathrm{TiO}_{3}$ and $\mathrm{Ba}_{0.8} \mathrm{Sr}_{0.2} \mathrm{TiO}_{3}$ films, which in turn increases their length. However, as the frequency increases, the longer dipoles find it harder to follow the applied field; as a result, a low dielectric constant is obtained. Furthermore, the trend of $\varepsilon$ at high frequencies agrees very well with the published results in the literature (Ru-Bing et al. 2005). The value of $\varepsilon$ in the whole frequency range is relatively high.

The variation of $\tan \delta$ as a function of frequency is given in Fig. 3. It can be observed from the figure that at low frequencies $\tan \delta$ decreases with increasing frequency and reaches a value close to zero at high frequencies. At a frequency range between 250 and $10^{5} \mathrm{~Hz}$, a broad peak in $\mathrm{Ba}_{0.7} \mathrm{Sr}_{0.3} \mathrm{TiO}_{3}$ and $\mathrm{Ba}_{0.8} \mathrm{Sr}_{0.2} \mathrm{TiO}_{3}$ is observed. This kind of peak occurs when the hopping frequency of electric charge carriers approximately equal that of the external applied AC electric field (Elkestawy et al. 2010); however, this peak becomes more noticeable and shifts toward lower frequencies as the strontium content decreases. This could

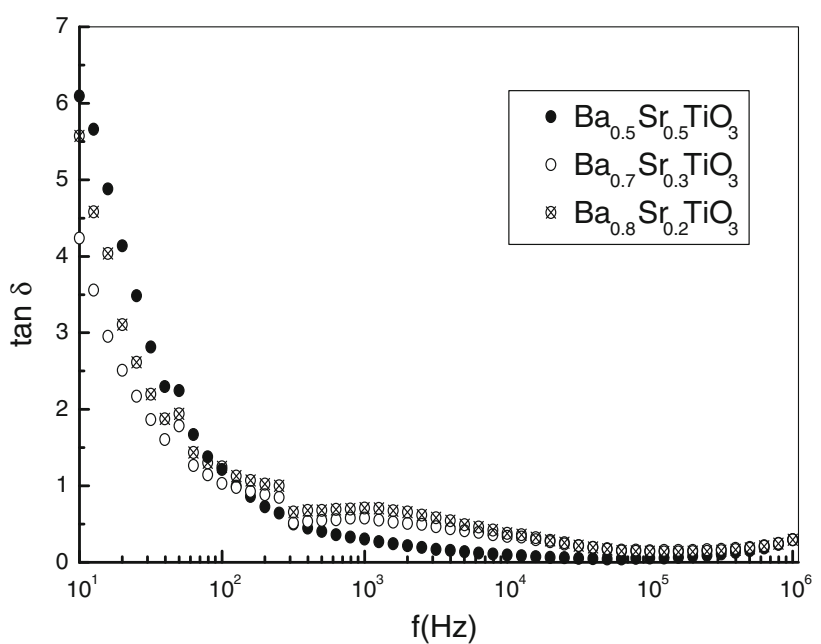

Fig. 3 Variation of $\tan \delta$ versus frequency for $\mathrm{Ba}_{0.5} \mathrm{Sr}_{0.5} \mathrm{TiO}_{3}$, $\mathrm{Ba}_{0.7} \mathrm{Sr}_{0.3} \mathrm{TiO}_{3}$, and $\mathrm{Ba}_{0.8} \mathrm{Sr}_{0.2} \mathrm{TiO}_{3}$ thin films within the MFM structure

be attributed to the increase of the grain sizes and dipoles present. From the above results for the MFM structure, it is shown that the dielectric properties of the films used in this work are relatively good.

In order to confirm the ferroelectric behavior of BST within the MFM samples, the capacitance-voltage (C-V) characteristics have been investigated. Figure 4 shows the $\mathrm{C}-\mathrm{V}$ characteristics for $\mathrm{Ba}_{0.5} \mathrm{Sr}_{0.5} \mathrm{TiO}_{3}, \mathrm{Ba}_{0.7} \mathrm{Sr}_{0.3} \mathrm{TiO}_{3}$, and $\mathrm{Ba}_{0.8} \mathrm{Sr}_{0.2} \mathrm{TiO}_{3}$ at $500 \mathrm{kHz}$ and at room temperature. The capacitance was measured while a DC field was swept from -7.5 to $+7.5 \mathrm{~V}$ and then reversed, with a sweeping rate of $0.01 \mathrm{~V} / \mathrm{s}$. For all the tested samples, it is observed that the capacitance varies non-linearly with the applied voltage. However, a well-defined butterfly shape with two peaks of the capacitance is observed; these peaks are formed as a result of a spontaneous polarization switching (Lahiry et al. 2000). This kind of hysteresis indicates that these films have a ferroelectric nature. The strength of the hysteresis increases as strontium content decreases, which could be attributed to the grain size and dipole dynamics. Furthermore, an observed asymmetry in the $\mathrm{C}-\mathrm{V}$ curves suggests that the films contain mobile ions or charges accumulated at the interface between the film and the electrode. In addition, there is a difference between the capacitance values of the two peaks, which may be due to some defect in energy levels in the film (Kumari et al. 2007). 

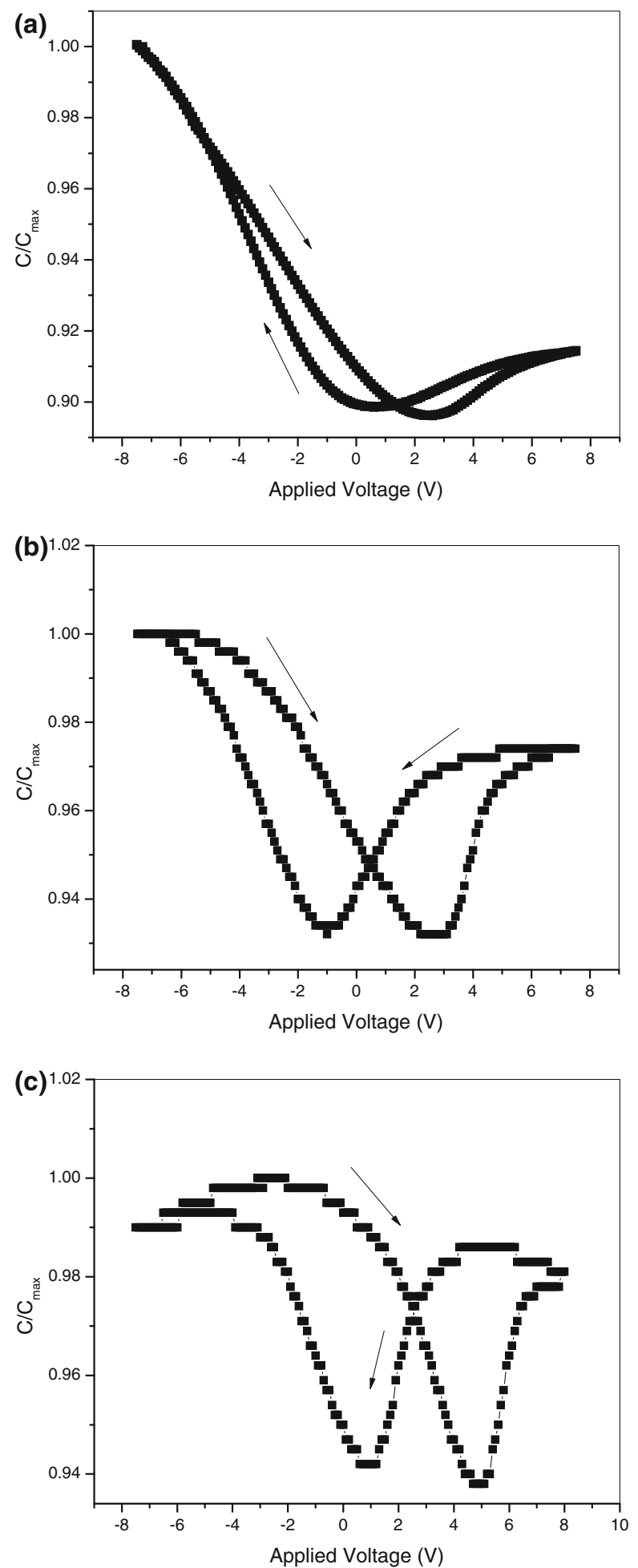

Fig. 4 The capacitance-voltage characteristics of a $\mathrm{Ba}_{0.5} \mathrm{Sr}_{0.5} \mathrm{TiO}_{3}$, b $\mathrm{Ba}_{0.7} \mathrm{Sr}_{0.3} \mathrm{TiO}_{3}$, and c $\mathrm{Ba}_{0.8} \mathrm{Sr}_{0.2} \mathrm{TiO}_{3}$ thin films within $\mathrm{MFM}$ configuration

The memory properties of the $\mathrm{Al} / \mathrm{BST} / \mathrm{SiO}_{2} / \mathrm{Si}$-gate (MFIS) structure were characterized by $\mathrm{C}-\mathrm{V}$ measurement using a Keithley 4200 semiconductor parameter analyzer.
Figure 5 shows typical $\mathrm{C}-\mathrm{V}$ characteristic curves for BST films within MFIS configuration, at a frequency of $1 \mathrm{MHz}$, and at room temperature. The applied DC bias swept from -20 to $+20 \mathrm{~V}$ and then reversed with a sweeping rate of $0.01 \mathrm{~V} / \mathrm{s}$. The $\mathrm{C}-\mathrm{V}$ plots show clockwise hysteresis loops as indicated by the arrows, corresponding to the ferroelectric polarization switching. This hysteresis is known as the memory window, and it occurs due to the flat-band voltage shift $\left(V \Delta_{\mathrm{FB}}\right)$ of the $\mathrm{C}-\mathrm{V}$ curves when the bias voltage is swept from accumulation to inversion and back (Roy et al. 2008).

It is observed that the $\mathrm{C}-\mathrm{V}$ curves shift toward the negative voltage axis, which indicates that a fixed positive charge is present at the interfaces, originating from oxygen vacancies that are formed during the heating and annealing treatment in ambient $\mathrm{O}_{2}$. This kind of shift is widely reported for different kind of ferroelectric materials (Bozgeyik et al. 2010; Juan et al. 2007). Furthermore, the sharp change in the capacitance at the accumulation and inversion region indicates that the interfaces of the junction are good.

The memory window for the $\mathrm{Ba}_{0.5} \mathrm{Sr}_{0.5} \mathrm{TiO}_{3}, \mathrm{Ba}_{0.7}$ $\mathrm{Sr}_{0.3} \mathrm{TiO}_{3}$, and $\mathrm{Ba}_{0.8} \mathrm{Sr}_{0.2} \mathrm{TiO}_{3}$ capacitors are 1.4, 3, and $3.3 \mathrm{~V}$, respectively. These values reveal that the memory window value increases as the strontium content decreases, in agreement with the trend of the ferroelectric hysteresis strength obtained for MFM samples. This increment is attributed to the dipoles present and grain size effects. XRD analysis reveals that $\mathrm{Ba}_{0.7} \mathrm{Sr}_{0.3} \mathrm{TiO}_{3}$ and $\mathrm{Ba}_{0.8} \mathrm{Sr}_{0.2}$ $\mathrm{TiO}_{3}$ films were crystallized with a tetragonal structure while $\mathrm{Ba}_{0.5} \mathrm{Sr}_{0.5} \mathrm{TiO}_{3}$ crystallized with a cubic structure, which leads to the valuable number of permanent dipoles that exist within the perovskite lattice of $\mathrm{Ba}_{0.7} \mathrm{Sr}_{0.3} \mathrm{TiO}_{3}$ and $\mathrm{Ba}_{0.8} \mathrm{Sr}_{0.2} \mathrm{TiO}_{3}$; these dipoles contribute to the ferroelectric behavior subsequently at the memory window width. On the other hand, as mentioned earlier in a previous work, the grain size of BST increases with the decreasing in the strontium content (Saif and Poopalan 2010). However, it has been reported that the ferroelectric properties, such as remnant polarization and coercive field, strongly depend on the grain size (Hongwei et al. 2006). Furthermore, Arlt et al. (1985) presented theoretical calculations showing that the density of the domain walls is inversely proportional to the square root of the grain, i.e., the density of the domain walls increases as the grain size decreases. This in turn strengthens the repulsive force between neighboring domain walls. As a result, the mobility for the domain wall reduces, which in turn makes the domain reorientation more difficult (Bozgeyik et al. 2010). Leading up to higher activation energy is required for the reorientation of the domains; as a result, the remnant polarization decreases, which reflects as a narrower memory window in $\mathrm{C}-\mathrm{V}$ curves. 

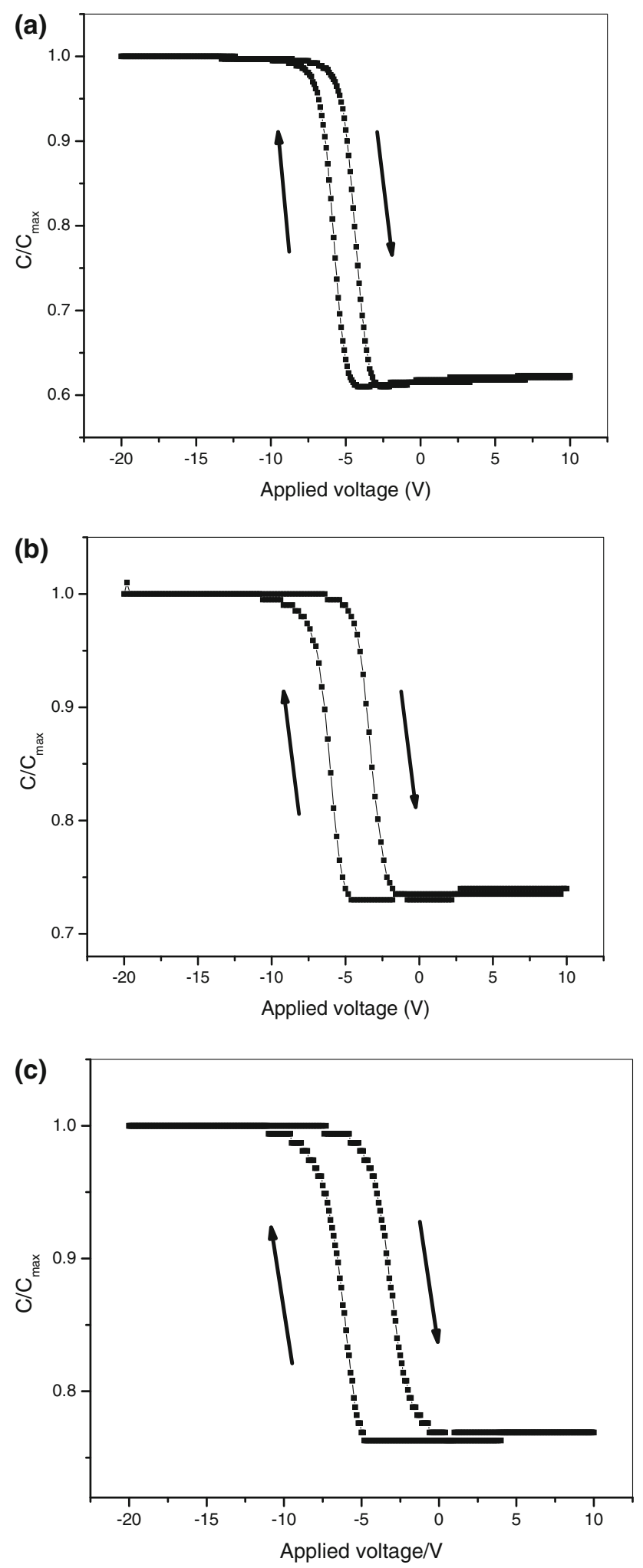

Fig. $5 \mathrm{C}-\mathrm{V}$ characteristics for a $\mathrm{Ba}_{0.5} \mathrm{Sr}_{0.5} \mathrm{TiO}_{3}, \mathbf{b} \mathrm{Ba}_{0.7} \mathrm{Sr}_{0.3} \mathrm{TiO}_{3}$, and $\mathbf{c} \mathrm{Ba}_{0.8} \mathrm{Sr}_{0.2} \mathrm{TiO}_{3}$ thin films within the MFIS configuration

Figure 6 shows a typical variation of leakage current density as a function of applied voltage $(\mathrm{J}-\mathrm{V})$ for $\mathrm{Ba}_{0.5} \mathrm{Sr}_{0.5} \mathrm{TiO}_{3}, \mathrm{Ba}_{0.7} \mathrm{Sr}_{0.3} \mathrm{TiO}_{3}$, and $\mathrm{Ba}_{0.8} \mathrm{Sr}_{0.2} \mathrm{TiO}_{3}$ within

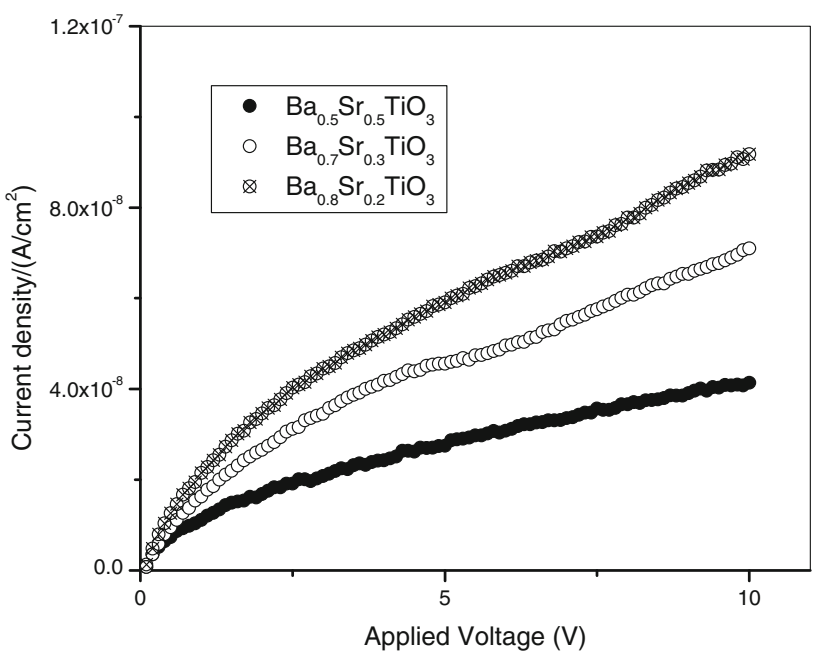

Fig. 6 Leakage current density for $\mathrm{Ba}_{0.5} \mathrm{Sr}_{0.5} \mathrm{TiO}_{3}, \mathrm{Ba}_{0.7} \mathrm{Sr}_{0.3} \mathrm{TiO}_{3}$, and $\mathrm{Ba}_{0.8} \mathrm{Sr}_{0.2} \mathrm{TiO}_{3}$ thin films within MFIS structure

MFIS structure at room temperature and for gate voltage swept from zero up to $10 \mathrm{~V}$. It is observed that the leakage current density increases as the applied voltage increases and as the strontium content decreases. It is found that for all the tested samples the leakage current density is of the order of $10^{-8} \mathrm{~A} / \mathrm{cm}^{2}$, at an applied voltage of $10 \mathrm{~V}$ $(0.23 \mathrm{MV} / \mathrm{cm})$. These values of the current density are relatively low, indicating that the films have good insulating characteristics. The increase of the leakage current density with the decrease of strontium content is attributed to the increase in the grain size. It is well known that the grain boundaries act as trappers for crystal defects (vacancies and dislocations) that interact with free carriers. As the grain size decreases the density of the grain boundaries increase, which leads to a larger amount of vacancies and dislocations, giving rise to high density of local charge accumulations. Those charge centers near the grain boundaries act to block the current flow, leading to low leakage current (Hu et al. 2004).

\section{Conclusion}

Nanocrystalline-ferroelectric $\mathrm{Ba}_{x} \mathrm{Sr}_{1-x} \mathrm{TiO}_{3}$ thin films with different $\mathrm{x}$ values have been fabricated as MFIS and MFM configurations using a sol-gel technique. The perovskite structure of the material has been confirmed via XRD. The $\varepsilon$ and $\tan \delta$ have been studied for MFM samples to insure the dielectric quality of the material. At low frequencies, $\varepsilon$ increases as the strontium content decreases, whereas at high frequencies, it shows the opposite variation, which is attributed to the dipole dynamics. $\tan \delta$ shows low values with a peak at the mid-frequency range. The ferroelectric memory window behavior of the MFIS samples has been 
investigated using $\mathrm{C}-\mathrm{V}$ characteristics. The results show that the memory window width increases as the strontium content decreases; this is attributed to the grain size and dipole dynamics effect. In addition, the leakage current density for the films was measured and was found to be of the order of $10^{-8} \mathrm{~A} / \mathrm{cm}^{2}$ for all tested samples, indicating that the films have insulating characteristics.

Open Access This article is distributed under the terms of the Creative Commons Attribution License which permits any use, distribution and reproduction in any medium, provided the original author(s) and source are credited.

\section{References}

Agarwal S, Sharma GL, Manchanda R (2001) Electrical conduction in (Ba, Sr)TiO thin film MIS capacitor under humid conditions. Solid State Commun 119:681-686. doi:10.1016/S0038-1098(01) 00284-8

Arlt G, Hennings D, De With G (1985) Dielectric properties of finegrained barium titanate ceramics. J Appl Phys 58:1619-1625. doi: $10.1063 / 1.336051$

Bozgeyik MS, Cross JS, Ishiwara H, Shinozaki K (2010) Characteristics of metal-ferroelectric-insulator-semiconductor structure using $\mathrm{Sr}_{0.8} \mathrm{Bi}_{2.2} \mathrm{Ta}_{2} \mathrm{O}_{9}$ and $\mathrm{SrBaZrO}$ for ferroelectric gates. Microelectron Eng 87:2173-2177. doi:10.1016/j.mee.2010.01.021

Elkestawy MA, Abdelkader S, Amer MA (2010) AC conductivity and dielectric properties of Ti-doped $\mathrm{CoCr}_{1.2} \mathrm{Fe}_{0.8} \mathrm{O}_{4}$ spinel ferrite. Phys B 405:619-624. doi:10.1016/j.physb.2009.09.076

Hongwei C, Chuanren Y, Chunlin F, Li Z, Zhiqiang G (2006) The size effect of $\mathrm{Ba}_{0.6} \mathrm{Sr}_{0.4} \mathrm{TiO}_{3}$ thin films on the ferroelectric properties. Appl Surf Sci 252:4171-4177. doi:10.1016/j.apsusc. 2005.06.027

Hu SH, Hu GJ, Meng XJ, Wang GS, Sun JL, Guo SL, Chu JH, Dai N (2004) The grain size effect of the $\mathrm{Pb}\left(\mathrm{Zr}_{0.45} \mathrm{Ti}_{0.55}\right) \mathrm{O}_{3}$ thin films deposited on LaNiO coated silicon by modified sol-gel process. J Cryst Growth 260:109-114. doi:10.1016/S0022-0248(03) 01592-6

Jha GC, Ray S, Manna I (2008) Effect of deposition temperature on the microstructure and electrical properties of $\mathrm{Ba}_{0.8} \mathrm{Sr}_{0.2} \mathrm{TiO}_{3}$ thin films deposited by radio-frequency magnetron sputtering. Thin Solid Film 526:3416-3421. doi:10.1016/j.tsf.2007.11.122

Juan PC, Jiang JD, Shih WC, Lee JYM (2007) The effect of annealing temperature on the electrical properties of metal-ferroelectric
$\left(\mathrm{Pb}_{0.47} \mathrm{Zr}_{0.53} \mathrm{TiO}_{3}\right.$ )-insulator ( $\mathrm{ZrO}$ )-semiconductor (MFIS) thinfilm capacitors. Microelectron Eng 84:2014-2017. doi:10.1016/ j.mee.2007.04.004

Kumari N, Krupanidhi SB, Varma KBR (2007) Dielectric, impedance and ferroelectric characteristics of c-oriented bismuth vanadate films grown by pulsed laser deposition. Mater Sci Eng B 138:22-30. doi:10.1016/j.mseb.2006.12.010

Lahiry S, Gupta V, Sreenivas K, Mansingh A (2000) Dielectric properties of sol-gel derived barium-strontium-titanate $\left(\mathrm{Ba}_{0.4} \mathrm{Sr}_{0.6}\right.$ $\mathrm{TiO}_{3}$ ) thin films. IEEE Trans Ultrason Ferroelectr Freq Control 47:854-860. doi:10.1109/58.852067

Lee CK, Kim WS, Park H, Jeon H, Pae YH (2005) Thermal-stress stability of yttrium oxide as a buffer layer of metal-ferroelectricinsulator-semiconductor field effect transistor. Thin Solid Film 473:35-339. doi:10.1016/j.tsf.2004.08.009

Panda B, Samantaray CB, Dhar A, Ray SK, Bhattacharya D (2002) Electrical properties of r.f. magnetron sputtered $\mathrm{Ba}_{x} \mathrm{Sr}_{1-x} \mathrm{TiO}_{3}$ films on multilayered bottom. J Mater Sci Mater Electron 13:263-268. doi:10.1023/A:1015591020730

Roy A, Dhar A, Bhattacharya D, Ray SK (2008) Structural and electrical properties of metal-ferroelectric-insulator-semiconductor structure of $\mathrm{Al} / \mathrm{SrBi}_{2} \mathrm{Ta}_{2} \mathrm{O} / \mathrm{Si}$ using $\mathrm{HfO}_{2}$ buffer. J Phys D Appl Phys 41:095408. doi:10.1088/0022-3727/41/9/095408

Ru-Bing Z, Chun-Sheng Y, Gui-Pu D, Jie F (2005) Preparation and characterization of $\mathrm{Ba}_{1-x} \mathrm{Sr}_{x} \mathrm{TiO}_{3}$ thin films deposited on $\mathrm{Pt} /$ $\mathrm{SiO}_{2} / \mathrm{Si}$ by sol-gel method. Mater Res Bull 40:1490-1496. doi: 10.1016/j.materresbull.2005.04.029

Saif AA, Poopalan P (2010) Impedance/modulus analysis of sol-gel $\mathrm{Ba}_{x} \mathrm{Sr}_{1-x} \mathrm{TiO}_{3}$ thin films. J Korean Phys Soc 57:1449-1455. doi: 10.3938/jkps.57.1449

Saif AA, Poopalan P (2011) Effect of the film thickness on the impedance behavior of sol-gel $\mathrm{Ba}_{0.6} \mathrm{Sr}_{0.4} \mathrm{TiO}_{3}$ thin films. Phys B 406:1283-1288. doi:10.1016/j.physb.2011.01.017

Tang MH, Zhou YC, Zheng XJ, Yan Z, Cheng CP, Ye Z, Hu ZS (2007) Structural and electrical properties of metal-ferroelectric-insulatorsemiconductor transistors using a $\mathrm{Pt} / \mathrm{Bi}_{3.25} \mathrm{Nd}_{0.75} \mathrm{Ti}_{3} \mathrm{O}_{12} / \mathrm{Y}_{2} \mathrm{O} / \mathrm{Si}$ structure. Solid State Electron 51:371-375. doi:10.1016/j.sse. 2006.11.014

Tripathi R, Kumar A, Bharti Ch, Sinh TP (2010) Dielectric relaxation of $\mathrm{ZnO}$ nanostructure synthesized by soft chemical method. Curr Appl Phys 10:676-681. doi:10.1016/j.cap.2009.08.015

Wang YP, Zhou L, Lu XB, Liu ZG (2003) C-V characteristics of Pt/ $\mathrm{PbZr}_{0.53} \mathrm{Ti}_{0.47} \mathrm{O}_{3} / \mathrm{LaAlO}_{3} / \mathrm{Si}$ and $\mathrm{Pt} / \mathrm{PbZr}_{0.53} \mathrm{Ti}_{0.47} \mathrm{O}_{3} / \mathrm{La}_{0.85} \mathrm{Sr}_{0.15}$ $\mathrm{CoO}_{3} / \mathrm{HfO} / \mathrm{LaAlO} / \mathrm{Si}$ structures for ferroelectric gate FET memory. Appl Surf Sci 205:176-181. doi:10.1016/S0169-4332(02) 01057-7 